\title{
A SNAPSHOT OF FEW BIOLOGICAL AND BIONOMICAL CHARACTERIS- TICS OFANOPHELES CULICIFACIES AND ANOPHELES ANNULARIS IN THREE MALARIOGENICALLY STRATIFIED DISTRICTS OF ODISHA, INDIA
} By

\author{
NITIKA PRADHAN ${ }^{1,2}$, RAJANI KANTA MAHAPATRA ${ }^{1}$, \\ And RUPENANGSHU K. HAZRA ${ }^{2^{\star}}$
}

School of Biotechnology, KIIT University ${ }^{1}$, and Regional Medical Research Centre ${ }^{2}$, Bhubaneswar-751023, Odisha, India (Correspondence: rupenkh@yahoo.co.in)

Abstract

Despite tremendous efforts over the past century, malaria remains the major health burden in the state Odisha, India. In view of designing a situation specific malaria control strategy, baseline data on bionomics of major Anopheles vectors were collected from three malariogenical stratified districts of Odisha. A comparative study of vector abundance, seasonal prevalence, habit/habitats, resting sites preference, parity rate, proportion of human blood fed vectors and Anopheline species composition was established in a high (Kalahandi), moderate (Bargarh) and a low endemic (Cuttack) districts, when malaria transmission was at its peak level. The mosquito collection showed a wide range of Anopheline fauna diversification with collection of two efficient malaria vectors i.e. An. culicifacies, the primary vector with a high peak value during monsoon and An. annularis, the secondary vector in three study districts. Both vectors was significantly more in indoor than outdoor in the three districts and among indoor collections, the density was higher in CS than HD whereas the density was more in HD than CS in Cuttack district for annularis. Similarly, their feeding, biting pattern as well as parity rate varies among these districts. The molecular identification of $A n$. culicifacies revealed the presence of all five sibling species viz. A, B, C, D \& E whereas only species A was detected out of two sibling species A \& B of An. annularis. These entomological indicators such as vector density, distribution, biology and bionomics as well as their vectorial attributes are important parameters to measure the pattern and intensity of malaria transmission. Proper monitoring and evaluation of these indices during the peak transmission period can reduce the increasing trend of malaria.

Key words: India, Malaria, Biology, Bionomics, Anopheles, Odisha

\section{Introduction}

Despite tremendous expansion in the financing and malaria control interventions, the disease continues to be a global health threat (Garcia, 2010). Odisha, an eastern state of India is highly endemic for malaria and bears almost a quarter of the country's total burden (Pradhan et al, 2016). There was no significant decline in malaria incidences for decades in spite of several programmatic efforts. However, this hyper-endemic state is now a role model not only in the country but also globe for its fight against malaria. Since 2017, India showed an impressive reduction in malaria cases out of all the eleven highest burden countries and the credit solely went to OdishaState. The possible reason for this success included increased political support, domestic funding, strong leadership, awareness programs and highly effective control interventions (WHO, 2018). By the initiative program DAMaN (Malaria Elimination in Remote Areas) Odisha did strong efforts on prevention, diagnosis and treatment of malaria. Apart from this, partnership of Abbott with State govt. system such as NVBDCP strengthens Odisha's malaria detection and surveillance system. Using past and present experiences Odisha has pledged to eliminate malaria by 2030 . Recent innovative vector/ malaria control intervention tools to increase confidence in elimination. But, to confront one of the major challenge i.e. asymptomatic malaria case detection, improved and more sensitive diagnostic methods need to be scaled up. Also, adequate health infrastructure, brief knowledge on prevalent vector species, the ecology, biology and bionomics, area specific intervention strategies as well as adequate research on parasite /vector's compl- 
ex molecular biology and new drugs and vaccine development will play a pivotal role in malaria elimination. There is an uneven distribution of intensity of malaria transmission across the globe. Environmental and topography factors determine the intensity of malaria transmission expressed as hyper-, meso-, and hypo-endemicity (Giles and Warrell, 1993). Malariogenic stratification was due to variable ecological conditions and climatic diversity that create a suitable environment for malaria vector responsible for variable vectorial attributes (Marten et al, 1995; Rao et al, 2015). Millions of people died annually as a result of this mosquito borne disease though it can be completely curable if diagnosed at an early stage but to completely prevent the disease an effective vector control was highly essential which relied on understanding of vector transmission dynamics (Russell et al, 2013). Distribution, abundance, habit/habitat preference feeding, resting, biting behavior, gonotrophic condition, infection status, parity rate of major Anopheles fauna were important factors affected the risk of malaria transmission (Kent et al, 2007; Tchuinkam et al, 2010; Tainchum et al, 2014). In the context of malaria elimination, the value of understanding the biology and bionomics of malaria vectors as their role in malaria transmission dynamics is highly critical. The present study highlighted some of these features of major Anopheline vector fauna in a high (Kalahandi district), moderate (Bargarh district) and a low endemic (Cuttack district) region of the state, Odisha. Hyper endemic district Kalahandi is situated in south western region of Odisha between latitude $19^{\circ} 3^{\prime} \mathrm{N}$ to $21^{\circ} 5^{\prime}$ $\mathrm{N}$ and longitude $82^{\circ} 30^{\prime} \mathrm{E}$ to $83^{\circ} 74^{\prime} \mathrm{E}$. The district is highly endemic for malaria, dominant with two major vector species viz. An. fluviatilis and An. culicifacies (Sharma et al, 2004; Sahu et al, 2017). But, the hypo endemic sub coastal district, Cuttack is located at $20^{\circ} 31^{\prime} 23^{\prime \prime} \mathrm{N}$ latitude and $85^{\circ} 49^{\prime} 60^{\prime \prime} \mathrm{E}$ longitude covering an area of $3932 \mathrm{~km}^{2}$ richer in few sibling species, An. culicifacies, \&
An. subpictus (Tripathy et al, 2010; Kumari et al, 2013). The moderate malaria endemic district, Bargarh is located in western Odisha at $21.33^{\circ} \mathrm{N} 82.62^{\circ} \mathrm{E}$ covering an area of $5,837 \mathrm{~km}^{2}$. Although a few reports regarding malaria vectors and their dynamics in specific areas of Odisha were available, but to the authors knowledge no systematic study was done on distribution, abundance, bionomics, attributes...etc. Last few years data showed that mortality graph continuously projected upwards, peaking in June and July, when there is arrival of monsoon season in the state. Few major vectorial features were investigated of dominant Anopheles mosquitoes in three malariogenically stratified districts where each of them represented a respective endemic zone during transmission peak.

\section{Materials and Method}

Study area and period: Kalahandi, Bargarh and Cuttack are the three districts of Odisha confined to south-western, western and eastern region of the state respectively (Fig. 1). On the basis of malariogenic stratification, thes three districts differ from each other in relation to API (Annual Parasite Incidence). The study was done over three years from January 2015 to December 2017.

Seasonal features: Odisha, lying just south of the Tropic of Cancer has a tropical climate. It experiences three well defined meteorological seasons: Summer (March-May), rainy (June-October) and winter (NovemberFebruary). The average rainfall is $150 \mathrm{~cm}$ directly influenced by the south-west monsoon and the month of July is the wettest period of the year. The monsoon shower during that period creates breeding ground for all sorts of mosquitoes including Anopheles species.

Mosquito collections: Anopheles species were collected from ten randomly selected malaria prone villages from each of the three districts. Eighteen houses from each village were selected and geographical information system (GPS) coordinates of each one were listed using differential GPS. Indoor resting mosquito collection was carried out twice /day in each village during morning (6:30- 
8:30 AM) and evening (6:30-8:30 PM) hours from cattle sheds (CS) \& human dwellings (HD). Majority of the houses were made of mud walls and thatched roofs. The indoor resting collection was performed by Pyrethrum Spray Catch early in the morning from 7:00 to 9:00hrs in 5-6 houses. Equal time was spent for collection of mosquitoes from different habitat and resting sites of each house/site using an oral aspirator and a flashlight. Outdoor collection from variety of environments, such as in dry pots, waste broken containers, water pipes, tree bases, tree holes, cracks and holes in the ground etc. Also, overnight collection was carried out using dry cell battery operated CDC light traps placed inside houses (near bed of occupants slept under insecticide treated nets) and cattle sheds operated from 18:00 to 6:00hrs. Next morning, mosquitoes were collected using an aspirator. All mosquitoes were transported to laboratory for identification and molecular processing.

Mosquito identification: Female Anopheles were identified using standard keys (Barraud, 1934; Habarch et al, 2007), sorted out based on abdominal conditions in field \& laboratory and dissected for parity status (WHO, 1975).

Sibling species of Anopheles: PCR identified primary Anopheline vector (An. culicifacies \& An. annularis), followed by methods standardized (Das et al, 2013; 2014).

Human blood meal screening: Each individual female mosquito was stored in a $1 \mathrm{ml}$ labeled micro-centrifuge tube with unique identifier. Genomic DNA was extracted after protocol of Barik et al. (2013), and PCR screened human blood (Rath et al, 2017).

Data analysis: Density of mosquitoes was expressed as number of female Anopheles collected/man/hour. One way ANOVA compared the mean density of total predominant Anopheline fauna among three districts during three different seasons. A two sample ttests compared habit and habitat preference of two vector species and the quantitative distribution of human blood fed Anopheles vectors species between three districts. Also, parity statuses of major vectors were compared by the Mann-Whitney U-test. KruskalWallis test determined significant variation among Anopheline vectors in Odisha districts, and analyzed by Microsoft Excel 2010 spread-sheets (Microsoft Corp., Redmond, WA, USA). P-value $<0.05$ was significant.

\section{Results}

As during monsoon period transmission rate was high in the state, some of the vector dynamics showed highlighted during such a period. Although An. subpictus was abundant in the three districts, but not find any vectorial potential/features. During the study quantitatively little no. of An. fluviatilis, An. minimus, An. stephensi and An. sundaicus, were collected even in high endemic Kalahandi district. But, the study focused only on An. culicifacies and An. annularis.

Seasonal distribution pattern of major Anopheline fauna in three districts: Adult mosquito collection from three areas showed a wide range of Anopheline fauna diversification with collection of two efficient malaria vectors i.e. An. culicifacies, the primary vector and An. annularis, the secondary vector. The per man hour density of An. culicifacies was higher in Kalahandi district as compared to other two study districts. One-way ANOVA data showed the density variations between seasons were highly significant during monsoon period $(\mathrm{p}<0.05)$ in Kalahandi without significant density variation between Bargarhand-Cuttack district. An. annularis did not show significant difference per man hour density related to season and area.

Resting habit and habitat of An. culicifacies and An. annularis (indoor vs. outdoor \& human dwelling vs. cattle shed): After seasonal prevalence, resting behavior of major Anopheles vectors during peak transmission period being an important entomological parameters supported transmission dynamics. T-test showed that density of both vectors was significantly more in indoor than outdoor $(\mathrm{p}<0.05)$ in all three districts. Density indoor collections was significantly higher in 
CS than HD in Kalahandi district for An. $\mathrm{Cu}$ licifacies $(\mathrm{p}<0.05)$. An. annularis density was more in CS than HD in Kalahandi and Bargarh without significant variation among both biotopes. A significant difference was between the two habitat in Cuttack district where it was more in HD than CS $(\mathrm{p}<0.05)$.

Biting activities of major Anopheles species: Each species nocturnal biting was expressed as number of mosquitoes collected from CS/HD. Anopheles culicifacies showed a peak biting rhythms between 12:00 AM to 3:00 AM in all three selected areas which indicated that the biting activity of An. culicifacies was not area dependent rather than slight variation in nocturnal biting preference between CS and HD. In An. annularis there was quite variation in biting preference, which ranged between 10:00PM to 4:00 AM with significant variation in CS and HD. The biting activity was higher in CS based on density. In human dwelling, peak biting time was during the wee hours in Kalahandi and Cuttack district, but in Bargarh district was between 9:00 to 10:00 PM.

Human blood feeding preference of major Anopheles species: Anthropophagic activity of Anopheles vectors $(\mathrm{N}=50)$ was expressed by human blood meal screening. A significant difference was between monsoon and summer/winter $(\mathrm{p}<0.05)$. Human blood fed of An. culicifacies \& An. annularis) was more in monsoon season as compared to other two seasons. Anthropophagic vectors were more in Kalahandi district in all seasons. While highlighting peak transmission period was among Kalahandi-Bargarh and KalahandiCuttack district for An. culicifacies. For An. annularis, significant variation in anthropophagic vectors was among Kalahandi-Bargarh and Cuttack-Bargarh District $(\mathrm{p}<0.05)$.

Parity: Parity rate of female Anopheles vectors $(\mathrm{N}=50)$ assessed age and longevity. A significant difference was between An. culicifacies parity rate in all districts (Kalahandi-Bargarh: $\mathrm{U}=0, \mathrm{z}=2.506, \mathrm{p}=0.012$; Kalahandi-Cuttack: $U=0, z=2.506, p=0.0128$; Bargarh-Cuttack: $U=1, z=2.29 \mathrm{p}=0.021$ ). A sig- ificant variation in parity rate of $A n$. annulais was detected between Kalahandi- Bargarh and Kalahandi-Cuttack district where as no significant difference was between Bargarh-Cuttack District (Kalahandi-Bargarh: U $=2.5, \mathrm{z}=1.98, \mathrm{p}=0.047$; Kalahandi-Cuttack: $\mathrm{U}=2.5, \mathrm{z}=1.984, \mathrm{p}=0.04$; Bargarh-Cuttack: $\mathrm{U}=12.5, \mathrm{z}=0.10 \mathrm{p}=0.920$ ).

Species composition of An. culicifacies \& An. annularis: Molecular identification of An. culicifacies $(\mathrm{N}=30)$ showed five sibling species viz. A, B, C, D \& E. Species B \& D was detected in all districts. Prevalence of species B was more in Kalahandi followed by Bargarh and Cuttack as prevalence of species D was observed in alternate manner i.e. more in Cuttack followed by Bargarh and Kalahandi district. Kruskal-Wallis test showed a significant difference among B \& D species among all districts $(\mathrm{Sp} \mathrm{B}: \mathrm{H}=9.05$, $\mathrm{p}=0.0107$; Sp D: $\mathrm{H}=10.33$, $\mathrm{p}=0.0056$ ). Sibling species $\mathrm{C} \& \mathrm{E}$ were only in Kalahandi and Bargarh district. Anopheles annularis $(\mathrm{N}=20)$ showed only sibling species $A$ in all districts without significant difference in relation to abundance $(\mathrm{H}=4.22, \mathrm{p}=0.121)$. Some vectors were not detected by PCR, and categorized as unidentified ones.

\section{Discussion}

Malaria is a vector-borne endemic disease msinly in tropical and subtropical ecosyst- ems which endemicity changes with change in ecological, climatic, and socio-developmental conditions (Sutherst, 2004; Patza et $a l, 2016)$. India accounts for about two-thirds of all malaria cases in Southeast Asia regions (WHO, 2011). The state, Odisha is high malaria transmission zone compared to other states of India (Das et al, 2006). Despite tremendous expansion in malaria control operations, it remained a long-lasting global health threat (Cohen et al, 2010). Its elimination efforts were hampered due to lack of proper transmission dynamics information (De Silva et al, 2012). A highly reliable and accurate transmission intensity measuring tool in endemic region was a must (Drakeley et al, 2003). Though, key determi- 
nants of malaria transmission included vector profile, environmental, ecological, socioeconomic and climatic factors that affected control efficacy (Sutherst, 2004; Louise et $a l, 2009)$. Malaria epidemicity is preventable by regular monitoring and screening of Anopheline vector(s), distribution and biology/ bionomics during the active transmission.

In Odisha, major primary vector species included An. fluviatilis, An. culicifacies and An. minimus whereas secondary vectors viz. An. annularis, An. subpictus, and An. varuna were the majority (Sahu et al, 2011; Dash, 2014; Sharma et al, 2015). An. culicifacies high prevalence in hyper-endemic Kalahandi area was in rainy season, which agreed with Pampana (1969) and Nagpal et al. (1983). But, secondary vector An. annularis did not show any seasonal prevalence in all districts. Density was visibly more during monsoon period, without significant variation as species didn't associate with seasonal rhythms in such areas. Also, statistical significance alone cannot uncloud the complex biological dynamics of vectors and climate factors. Majority of villages were surrounded by open field and dense forest, mosquito species were distributed widely and was very difficult for outdoor collection. This reason might be due to lower vector density in outdoor than indoor in the three districts. An. culicifacies and An. annularis were predominantly zoophlic and preferred cattle sheds (Waite et $a l, 2017)$. In the present study, An. culicifacies were found in greater densities in cattle sheds (CS) rather than human dwelling (HD) in all districts. The availability of eaves and crevices of thatched cattle sheds provide a preferential environment for vector species and easy availability of hosts without any repellent pressure. Targeting the zoophagic vectors provided a cost effective for efficient vector control to eliminate malaria (Waite $e t$ al, 2017). An. annularis was more dominant in CS than in HD except in Cuttack area, as some species might alter their behavior to the anthropophlic ones. A species specific endogenous circadian rhythm regulated the mosquitoes daily activities that explained why several Anopheles species in same habitat exploit their attributes at different times (Beck, 1968). Few studies declared possibility of genetic factors in influencing mosquito biting rhythms (Reisen et al, 1978). Accurate data on biting pattern of Anopheles vectors was a prerequisite for mounting any control intervention. In the present study, the peak biting activities of An. culicifacies \& An. annularis were evaluated by hourly collection from 18:00 to 6:00hrs in both CS and HD. Biting peak rates of Anopheles species synchronize with the inhabitants activities. Anopheles culicifacies generally prefers biting at midnight but few found that the activities increase during night early hours in human dwelling (Singh et al, 1995). An. culicifacies exhibited a typical nocturnal biting pattern followed by appearance of a sharp peak in midnight. The biting rate for $A n$. annularis was more in CS than HD which revealed the behavioral plasticity of that species tended to avoid any intervention, protective measures or repellent pressure in HD. Further, area wise variation in the peak period indicated the adaptive feature of these species to avoid competition for hosts. The success of malaria elimination depends on all entomological indices to better understanding biology and bionomics of mosquito vectors. One of such parameter is the human blood fed proportion, more commonly anthropophagic vectors to determine host preferences and vectorial importance. Greater frequency of feeding on humans increased species vectorial capacity. Anopheles fauna in Odisha displayed the high anthropophlic index (AI) of secondary vector An. annularis as compared to primary vector An. culicifac ies (Parida et al, 2007).

In the present study, high proportions of anthropophagic vectors were collected from Kalahandi district. Due to greater abundance of human blood fed vectors, Kalahandi district exhibited a higher incidence of malaria than other two districts. The high density of anthropophagic annularis vectors in Cuttack 
district during monsoon season may favor disease transmission in some endemic pockets. But, meso-endemic Bargarh district was not significantly influenced by this parameter that showed some other factors like climatic, ecological, socio-economic, demographic that might regulate the endemicity in this district.

Estimation of parity rate of female Anopheles vectors reflected the epidemiological importance of vector populations (Barbosa et al, 2016). In this study, the parity rate data showed a defined pattern where the rate was high in hyper-endemic Kalahandi followed by moderate-endemic Bargarh and low endemic Cuttack district for An. culicifacies. Though, An. annularis showed the similar pattern, slight deviation occurred almost in Bargarh and Cuttack district. The high parity rate indicated that majority of mosquitoes in high malarigenous areas obtain blood meal and complete at least one or more gonotrophic cycles and have high survival rate and vectorial capacity. The high parity rate also highlighted the abundance of older female vectors in that area due to failure of any vector control strategy. The monsoon season is usually the malaria transmission season in the state, and this high parity rate was behind high survival index of vectors and disease transmission.

In the present study, An. culicifacies predominante in these districts, and fewer $A n . f l$ uviatilis were identified during that period, but predominant primary malaria vectors in southern districts (Sahu et al, 2008). The sibling species (A, B, C, D, \& E) of Culicifacies complex were prevalent in Odisha with $\mathrm{B}$ the predominance species, but $\mathrm{E}$ was an efficient vector (Tripathy et al, 2010; Das et al, 2013). All sibling species of culicifacies in Kalahandi district with predominated species B. Species A \& C were absent in Bargarh and Cuttack respectively. Species D was predominant in Bargarh district. Anthropophlic species E was prevalent in Kalahandi followed by Bargarh district due to anthropophlic species complexes which slowly in- creased endemicity in Bargarh district to hyper-endemicity in Kalahandi district. An. annularis and An. culicifacies were predominant all year around. During high transmission period among annularis sibling species, only A was abundant in all districts. This agreed with Das et al. (2014) who detected An. annularis A with potential vectorial capacity from 13 endemic districts of Odisha. New cryptic species emerged, it becomes increasingly apparent to study their genetic diversity to identify them and vectorial attributes for planning effective vector control strategies (Stevension and Norris, 2017).

\section{Conclusion}

The present data showed that malaria transmission did not change its pattern and intensity rather the ruling vectors and their attributes were the key determinants associated with transmission. Feasible control activities must be based on understanding epidemiology of malaria in the targeted area, vector species involved transmission dynamics and their behavior. This provided a baseline for evidence based planning and implementation of malaria control strategies.

\section{Acknowledgements}

The authors are grateful to Dr. S. Pati, Director of Regional Medical Research Centre, Bhubaneswar. Thanks also extend to School of Biotechnology, KIIT University, Bhubanswar, India. This work was kindly supported by a research grant from the Indian Council of Medical Research, New Delhi [6/97(107)/2015-ECD-II].

Conflict of interest: The authors have no conflicts of interest.

\section{References}

Barbosa, LMC, Sauto, RNP, Ferreira, RMA, Scarpassa, VM, 2016: Behavioral patterns, parity rate and natural infection analysis in anophelines species involved in the transmission of malaria in the north-eastern Brazilian Amazon region. Acta Trop. 164:216-25.

Barik, SK, Hazra, RK, Prusty, MR, Rath, A, Kar, SK, 2013: .A simple, rapid and very efficient protocol for DNA isolation from mosquito species. Protoc. Exch. doi: 10.1038/protex.

Barraud, PJ, 1934: The Fauna of British India, 
including Ceylon and Burma. Diptera. Vol V. Family Culicidae Tribes Megarhinini and Culicini. Taylor and Francis, London 5.

Beck, SD, 1968: Insect photoperiodism: Academic Press, New York and London.

Cohen, JM, Moonen, B, Snow, RW, Smith, D L, 2010: How absolute is zero? An evaluation of historical and current definitions of malaria elimination. Malar. J. 9:213.

Das, B, Patra, AP, Das, M, Mahapatra, N, Tripathy, HK, et al, 2014: Vectorial capacity and genetic diversity of Anopheles annularis (Diptera: Culicidae) mosquitoes in Odisha, India from 2009 to 2011. Acta Trop. 137:130-9.

Das, LK, Pani, SP, 2006: Clinical manifestations of severe forms of $P$. falciparum malaria in Koraput district of Orissa state, India. J. Vect. Borne Dis. 43, 3:140-3.

Das, M, Das, B, Patra, AP, Tripathy, HK, Mohapatra, N, et al, 2013: Anopheles culicifacies sibling species in Odisha, eastern India: First appearance of Anopheles culicifacies E and its vectorial role in malaria transmission. Trop. Med. Int. Hlth. 18:810-21.

Dash, S, 2014: Morphological and molecular characterization of genus Anopheles (Diptera: Culicidae) of Ganjam District Orissa, India. Rec. Zool. Surv. India 114:317-40.

De Silva, PM, Marshall, JM, 2012: Factor contributing to urban malaria transmission in SubSaharan Africa: A systematic review. J. Trop. Med. https://doi: 10.1155/2012/819563.

Drakeley, C, Schellenberg, D, Kihonda, J, Sousa, CA, Arez, AP, et al,2003: An estimation of entomological inoculation rate for Ifakara: A semi-urban area in a region of intense malaria transmission in Tanzania. Trop. Med. Int. Hlth. 8: 767-74.

Garcia, LS, 2010: Malaria. Clin. Lab. Med. 30, 1:93-129.

Giles, HM, Warrell, DA, 1993: Bruce-Chwatt's Essential Malariology, $3^{\text {rd }}$ ed. London: Edward Arnold.

Harbach, RE, 2004: The classification of genus Anopheles (Diptera: Culicidae): A working hypothesis of phylogenetic relationships. Bull Entomol Res. 94:537-53.

Kelly-Hope, LA, Hemingway, J, McKenzie, F E, 2009: Environmental factor associated with the malaria vectors Anopheles gambiae and Anopheles funestus in Kenya. Malar. J. 8:268.

Kent, RJ, Thuma, PE, Mharakurwa S, Norris, DE, 2007: Seasonality, blood feeding behav- ior and transmission of Plasmodium falciparum by Anopheles arabiensis after an extended drought in Southern Zambia. Am. J. Trop. Med. Hyg. 76:267-74.

Kumari, S, Das, S., Mahapatra, N, 2013: Anopheles subpictus $\mathrm{B}$ and its role in transmission of malaria in Odisha, India, Trop. Biomed. 30:7107.

Marten, WJM, Niessen, LW, Rotmans, J, Jetten, TH, McMichael, AJ, 1995: Potential impact of global climate change on malaria risk. Environ. Hlth. Perspect. 103:458-64

Nagpal, BN, Sharma, VP, 1983: Mosquitoes of Coastal Orissa. Indian J. Malariol. 2:141-5.

Pampana, E, 1969: A Textbook of Malaria Eradication. $2^{\text {nd }}$ Edition, Oxford University Press, London.

Parida, S.K. Hazra, RK, Marai, N, Tripathy, HK, Mahapatra, N, 2007: Host feeding patterns of malaria vectors in India. J. Am. Mosq. Control Assoc. 22, 4:629-34.

Patza, JA, Graczykb, TK, Gellera, N, Vittor, AY, 2000: Effects of environmental change on emerging parasitic diseases. Int. J. Parasitol. 30: 1395-405.

Pradhan, A, Anasuya, A, Pradhan, MM, Kavitha, AK, Kar, P, et al, 2016: Trends in malaria in Odisha, India- An Analysis of the 2003-2013 time series Data from the National Vector Borne Disease Control Programme. Plos One 11:1-16.

Rao, MRK, Padhy, RN, Das, MK, 2015: Surveillance on malaria and dengue vectors fauna across in Angul District Of Odisha, India: An approach to determine their diversity and abundance, correlation with the ecosystem. J. Entomol. Zool. Stud. 3:459-69.

Rath, A, Prusty, MR, Barik, SK, Das, M, Tripathy, HK, et al,2017: Development, standardization and validation of molecular techniques for malaria vector species identification, trophic preferences and detection of Plasmodium falciparum. J. Vect.Borne Dis. 54:25-34.

Reisen WK, Aslam khan M, 1978: Biting rhytms of some Pakistan mosquitoes (Diptera: Culicidae). Bull. Entomol. Res, 68:313-30.

Russell, TL, Beebe, NW, Cooper, RD, Lobo, NF, Burkot, TR, 2013: Successful malaria elimination strategies require interventions that target changing vector behaviors. Malar J. 12:5661.

Sahu, SS, Gunasekaran, K, Jambulingam, P, Krishnamoorty, N, 2008: Identification of Anopheles fauna in a hyper endemic falciparum area 
of Orissa State, India. Ind. J. Med. Res. 127, 2: $178-82$

Sahu, SS, Gunasekaran, K, Krishnamoorthy, N, Vanamail, P, Mathivanan, A, et al, 2017: Bionomics of Anopheles fluviatilis and Anopheles culicifacies (Diptera: Culicidae) in relation to malaria transmission in East-Central India. J. Med. Entomol. 54:821-30.

Sahu, SS, Gunasekaran, K, Vanamail, P, Jambulingam, P, 2011: Seasonal prevalence and resting behaviour of Anopheles minimus Theobald and An. fluviatilis James (Diptera: Culicidae) in east-central India. Ind. J. Med. Res. 133:65561.

Sharma, SK, Upadhyay, AK, Haque, MA, Singh, OP, Adak, T, et al,2004: Insecticide susceptibility status of malaria vectors in some hyper-endemic tribal districts of Orissa. Curr. Sci. 87:1718-26.

Sharma, VP, Dev, V, 2015: Biology \& control of Anopheles culicifacies Giles 1901. Ind. J. Med. Res. 141:525-36.

Singh, S, Singh, RP, Jauhari, RK, 1995: Biting activity of the malaria vector, Anopheles culicifacies, on man and cattle in Doon valley, India. Appl. Parasitol. 36:185-91.

Stevenson, JC, Norris, DE, 2017: Implicating cryptic and novel Anophelines as malaria vectors in Africa. Insects 8, 1:1
Sutherst, RW, 2004: Global change and human vulnerability to vector-borne diseases. Clin. Microbiol. Rev.17, 1:136-73.

Tainchum, K, Ritthison, W, Chuaycharoensuk, T, Bangs, M, Manguin, S, et al, 2014: Diversity of Anopheles species and trophic behaviour of putative malaria vectors in two malaria endemic areas of north-western Thailand. J. Vector Ecol. 39:424-36.

Tchuinkam, T, Simard, F, Lele-Defo, E, TeneFossog, B, Tateng-Ngouateu A, et al, 2010: Bionomics of Anopheline species and malaria transmission dynamics along an altitudinal transect in Western Cameroon. BMC Infect. Dis. 10:119. Tripathy, A, Samanta, L, Das, S, Parida, SK, Marai, N, et al, 2010: Distribution of sibling species of Anopheles culicifacies s.l. and Anopheles fluviatilis s.l. and their vectorial capacity in eight different malaria endemic districts of Orissa, India. Mem. Inst. Oswaldo Cruz 105:981-7.

Waite, JL, Swain, S, Lynch, PA, Sharma, SK, Haque, MA, et al, 2017: Increasing the potentiial for malaria elimination by targeting zoophilic vectors. Sci. Rep. 7:40551.

WHO, 1975: Manual on Practical Entomology. Pt II: Method and techniques, Geneva.

WHO, 2011: World Malaria Report, Geneva.

WHO, 2018: World Malaria Report, Geneva.

\section{Explanation of figures}

Fig. 1: Odisha map showed study areas viz. Cuttack, Bargarh and Kalahandi district.

Fig. 2: Seasonal distribution of two major Anopheline fauna in Kalahandi, Bargarh and Cuttack district. Error bar= standard error of mean.

Fig. 3: Habit and habitat preference of major Anopheles species in Kalahandi, Bargarh and Cuttack district of Odisha. Error bar= standard mean error.

Fig. 4: Biting activity of major Anopheline vectors in Kalahandi, Bargarh and Cuttack district of Odisha. CS-cattle shed; HD-human dwelling, mosquito density in number.

Fig. 5: Human blood fed An. culicifacies and An. annularis density in summer, monsoon and winter season. Error bar= standard mean error Fig. 6: Parity rate of An. culicifacies and An. annularis in Kalahandi, Bargarh and Cuttack district. Error bar= standard mean error.

Fig.7: Species composition and distribution of major Anopheline fauna in Kalahandi, Bargarh and Cuttack district. Error bar= standard mean error.

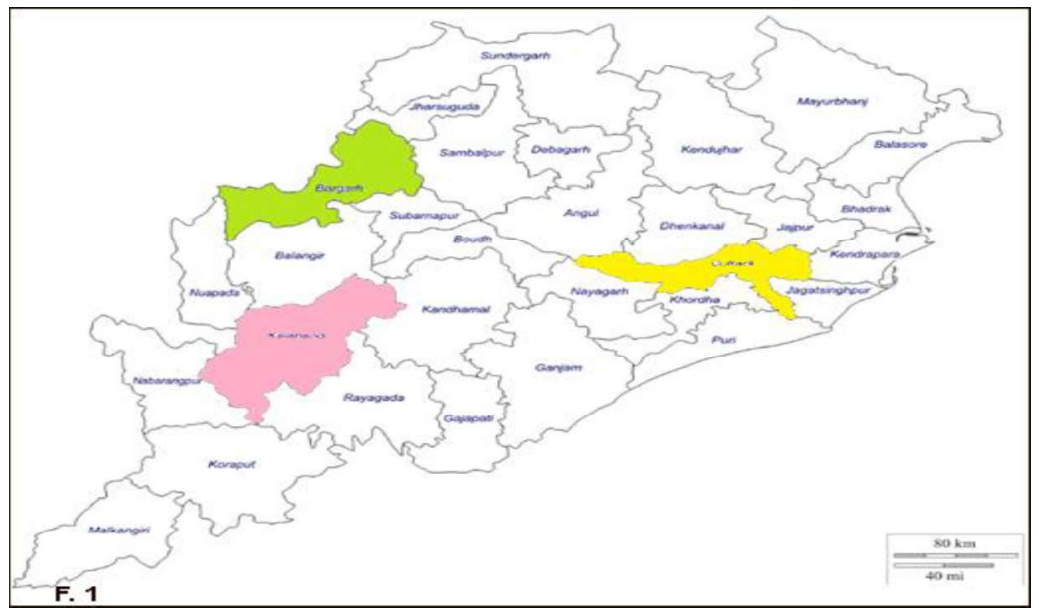



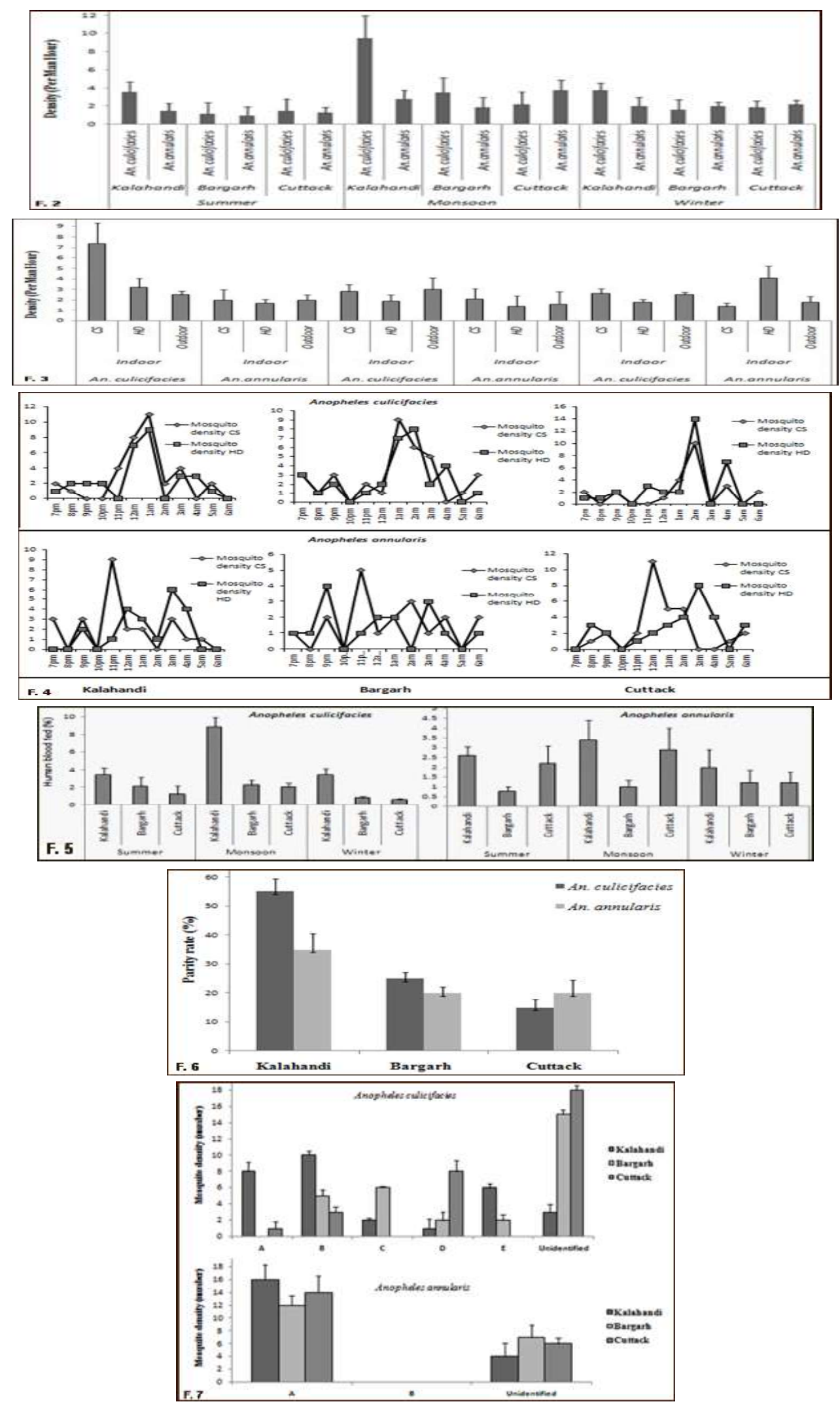